\title{
Treatment of advanced soft-tissue sarcomas using a combined strategy of high-dose ifosfamide, high-dose doxorubicin and
} salvage therapies

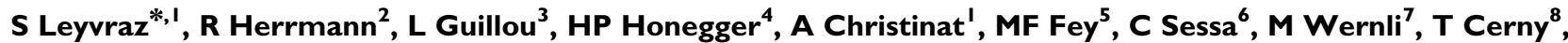 D Dietrich' and B Pestalozzi ${ }^{10}$ for the Swiss Group for Clinical Cancer Research (SAKK)}

'Centre Pluridisciplinaire d'Oncologie, University Hospital, CHUV BH06, Rue du Bugnon 46, 1011 Lausanne, Switzerland; ${ }^{2}$ Medical Oncology Clinic, University Hospital, Basel, Switzerland; ${ }^{3}$ Pathology Institute, University Hospital, Lausanne, Switzerland; ${ }^{4}$ Triemli City Hospital, Zurich, Switzerland; ${ }^{5}$ Institute of Medical Oncology, Inselspital, Bern, Switzerland; ' Istituto Oncologico della Svizzera italiana, Bellinzona, Switzerland; ${ }^{7}$ Oncology Hematology Department, Kantonsspital, Aarau, Switzerland; ${ }^{8}$ Oncology/Hematology, Kantonsspital, St. Gallen, Switzerland; ${ }^{9}$ SAKK Coordinating Center, Bern, Switzerland; ${ }^{10}$ Department of Oncology, University Hospital, Zurich, Switzerland

\begin{abstract}
Having determined in a phase I study the maximum tolerated dose of high-dose ifosfamide combined with high-dose doxorubicin, we now report the long-term results of a phase II trial in advanced soft-tissue sarcomas. Forty-six patients with locally advanced or metastatic soft-tissue sarcomas were included, with age $<60$ years and all except one in good performance status (0 or I). The chemotherapy treatment consisted of ifosfamide $10 \mathrm{~g} \mathrm{~m}^{-2}$ (continuous infusion for 5 days), doxorubicin $30 \mathrm{mg} \mathrm{m}^{-2} \mathrm{day}^{-1} \times 3$ (total dose $90 \mathrm{mg} \mathrm{m}^{-2}$ ), mesna and granulocyte-colony stimulating factor. Cycles were repeated every 2 I days. A median of 4 ( I -6) cycles per patient was administered. Twenty-two patients responded to therapy, including three complete responders and 19 partial responders for an overall response rate of $48 \%$ (95\% Cl: 33-63\%). The response rate was not different between localised and metastatic diseases or between histological types, but was higher in grade 3 tumours. Median overall survival was 19 months. Salvage therapies (surgery and/or radiotherapy) were performed in $43 \%$ of patients and found to be the most significant predictor for favourable survival (exploratory multivariate analysis). Haematological toxicity was severe, including grade $\geqslant 3$ neutropenia in $59 \%$, thrombopenia in $39 \%$ and anaemia in $27 \%$ of cycles. Three patients experienced grade 3 neurotoxicity and one patient died of septic shock. This high-dose regimen is toxic but nonetheless feasible in multicentre settings in non elderly patients with good performance status. A high response rate was obtained. Prolonged survival was mainly a function of salvage therapies.

British Journal of Cancer (2006) 95, I342- |347. doi: I0.1038/sj.bjc.6603420 www.bjcancer.com
\end{abstract}

Published online 10 October 2006

(C) 2006 Cancer Research UK

Keywords: doxorubicin; ifosfamide; salvage surgery; soft-tissue sarcomas

Soft-tissue sarcomas are a highly heterogeneous group of tumours with a low incidence. At least 50 different subtypes are distinguished, each with its specific biology and clinical outcome. The majority of these tumours are presumably derived from mesoderm and categorised by the normal tissue they resemble. As they are uncommon, however, they are subsumed under the collective term soft-tissue sarcoma and therapeutically approached in similar ways.

In recent years, progress has been made in understanding their clinical and biological complexity (Dirix and Van Oosterom, 1999; Fayette and Blay, 2005), such that oncologists have increasingly been able to define customised therapies. Paclitaxel has been found to be active mainly in patients with angiosarcomas (Fata et al, 1999). Docetaxel combined with gemcitabine has been shown to induce a $53 \%$ response rate in leiomyosarcomas of gynaecological

*Correspondence: Dr S Leyvraz; E-mail: Serge.Leyvraz@chuv.ch Received 21 June 2006; revised 7 September 2006; accepted 13 September 2006; published online 10 October 2006 origin (Hensley et al, 2002). Topoisomerase inhibitors are active for rhabdomyosarcomas (Cosetti et al, 2002). Trabectedin (ET743) has a low objective response rate but led to stable disease in $24 \%$ of pretreated patients (Yovine et al, 2004) and was mainly active in myxoid liposarcomas (Grosso et al, 2006).

The most common approach used in all histological subtypes, however, is to use doxorubicin and ifosfamide (Edmonson et al, 1993). Their anti-tumour activity as single agents does not exceed $15-25 \%$. Combining these agents might be more effective but has not been shown to improve survival in a significant way compared to their use as single agents (Santoro et al, 1995).

Following suggestions that these agents may have a doseresponse relationship (O’Bryan et al, 1973; Le Cesne et al, 1995; Cerny et al, 1999), various phase-I and -II trials were performed in which they were administered at high doses, yielding response rates of 40-66\% (Frustaci et al, 1997; Patel et al, 1998; Reichardt et al, 1998; Maurel et al, 2004a). In some studies, median overall survival was up to 24 months. There are also suggestions that applying regimens with high response rates may render an initially inoperable tumour operable, thereby improving the outcome (Judson, 2004). 
In a previous study, we defined the maximum tolerated dose of doxorubicin combined with ifosfamide, administered every 3 weeks and supported by haematopoietic growth factors (Leyvraz et al, 1998). The maximum tolerated dose of doxorubicin was $60 \mathrm{mg} \mathrm{m}^{-2}$ with ifosfamide at $12 \mathrm{~g} \mathrm{~m}^{-2}$ and could be increased to $90 \mathrm{mg} \mathrm{m}^{-2}$ with ifosfamide at $10 \mathrm{~g} \mathrm{~m}^{-2}$. Myelosuppression was severe but resolved within 4 days.

On this basis, we designed a multicentre nonrandomised phaseII trial for advanced and metastatic soft-tissue sarcomas. Salvage surgery and/or radiotherapy with the aim of removing all residual tumour tissue was performed whenever such an approach was considered appropriate to render patients free of disease.

\section{PATIENTS AND METHODS}

The protocol was in accordance with the Declaration of Helsinki principles and was approved by the respective responsible ethics commissions. All patients included in the study gave their written informed consent.

\section{Inclusion criteria}

Patients with histologically demonstrated advanced or metastatic soft-tissue sarcoma were eligible for the study. Excluded were patients with histological evidence of malignant mesothelioma, chondrosarcoma, neuroblastoma, osteosarcoma, Ewing sarcoma and embryonal rhadomyosarcoma.

Additional eligibility criteria included the presence of measurable disease in one or two dimensions as demonstrated by physical examination or imaging techniques. Ascites and pleural effusions were not considered measurable. Patients were only included if they were $18-70$ years old and showed a performance status of $\leqslant 2$ as defined by the Eastern Cooperative Oncology Group (ECOG) (Oken et al, 1982). They were not included in the presence of previous chemotherapy, previous radiotherapy on recurrent disease, or CNS metastases. Another exclusion criterion was abnormal haematological, renal or hepatic function. Cardiac function was required to be within the normal range on echocardiography or multigated nuclear scanning.

\section{Study design and treatment plan}

This was a multicentre, single-arm phase II trial (protocol SAKK 57/93). Chemotherapy cycles were repeated every 3 weeks as follows: (i) ifosfamide $10 \mathrm{~g} \mathrm{~m}^{-2}$ i.v. as continuous infusion over 5 days; (ii) mesna $2 \mathrm{~g} \mathrm{~m}^{-2}$ day $^{-1}$ i.v. as continuous infusion over 6 days; (iii) doxorubicin $30 \mathrm{mg} \mathrm{m}^{-2}$ day $^{-1}$ i.v. bolus given for 3 days (total dose $90 \mathrm{mg} \mathrm{m}^{-2}$ ), starting $4 \mathrm{~h}$ after initiation of ifosfamide on day 1; and (iv) granulocyte-colony stimulating factor (G-CSF, Filgrastim) $5 \mu \mathrm{g} \mathrm{kg}^{-1}$ s.c. once daily as of day 6 for 10 days or - if neutrophile counts were $<500 \mu \mathrm{l}^{-1}$ by that time - for a total of 14 days.

\section{Response, toxicity assessment, dose modification and pathology review}

Response in up to three measurable lesions was assessed by tumour evaluation according to standard WHO criteria (World Health Organization, 1979). Each observed complete or partial response had to be confirmed at least 4 weeks later. CT scans were obtained at baseline, after every other chemotherapy cycle, and at the end of the treatment. Toxicity was assessed based on WHO grading, and neurotoxicity based on MD Anderson scores (Castellanos and Fields, 1986).

Subsequent treatment cycles were delayed by 1 or 2 weeks if $<3500 \mu \mathrm{l}^{-1}$ leukocytes or $<100000 \mu \mathrm{l}^{-1}$ platelets were measured at day 22. Dose modifications were performed: (i) if i.v. antibiotics were required during myelosuppression or in case of thrombocytopenia-related bleeding, by reducing ifosfamide to $8 \mathrm{~g} \mathrm{~m}^{-2}$; (ii) in the presence of WHO grade $\geqslant 3$ mucositis, by reducing doxorubicin to $75 \mathrm{mg} \mathrm{m}^{-2}$. The dose of doxorubicin was not reduced after myelosuppression. Ifosfamide could be increased to $12 \mathrm{~g} \mathrm{~m}^{-2}$ after normal recovery from myelosuppression without febrile episodes requiring the use of i.v. antibiotics. Dose intensity was calculated in $\mathrm{mg} \mathrm{m}^{-2}$ week $^{-1}$ for each patient (Hryniuk and Goodyear, 1990).

In case the MD Anderson score was $\geqslant 2$, an attempt was made to manage the neurotoxic event by administering methylene blue rather than decreasing the dose of ifosfamide. Methylene blue was then administered as an i.v. bolus of $50 \mathrm{mg}$ repeated at the same dose every $2 \mathrm{~h}$, or as continuous infusion at $200 \mathrm{mg} \mathrm{day}^{-1}$ diluted in 5\% dextrose, until the event resolved (Küpfer et al, 1994).

Cardiotoxicity was monitored by assessing cardiac ejection fraction every 2-3 cycles and prior to chemotherapy cycles on reaching doxorubicin cumulative doses of $>450 \mathrm{mg} \mathrm{m}^{-2}$. Chemotherapy was discontinued if cardiac ejection fraction dropped to $<40 \%$. Chemotherapy was not administered in the presence of serum creatinine $>150 \mu \mathrm{moll}^{-1}$ or creatinine clearance $<60 \mathrm{ml} \mathrm{min}^{-1}$.

Pathology specimens were reviewed by an independent group of expert pathologists led by LG to confirm diagnosis and tumour grade based on the FNCLCC grading system (Guillou et al, 1997).

\section{Statistical methods}

The primary end point of the study was the tumour response rate based on WHO criteria. Simon's optimal two-stage design was used to calculate the number of patients to be included in the phase-II trial, based on the premise that a response rate of $<40 \%$ would disqualify the treatment regimen, while a response rate of $\geqslant 70 \%$ would render it a promising option. To obtain a significance level of $5 \%$ at a power of $80 \%$, a total number of 46 patients were required, with 16 of them in the stage-I and another 30 in the stage-II phase. After the first 16 patients had been evaluated for their response to chemotherapy, it was decided that the trial should be continued until the target number of 46 patients was reached. At least 24 responses among the 46 patients were required to consider the treatment promising.

Confidence intervals for response rates were calculated using the Clopper-Pearson method. Time to progression was calculated for all patients from the time of enrollment until disease progression or death, with censoring at last follow-up. Survival times were calculated from enrollment to death or last follow-up. The Kaplan-Meier was used to estimate the median values of time to progression and survival. Log-rank test was used to evaluate differences in survival. Cox regression was used for exploratory multivariate analysis of survival. The following variables, represented by appropriate binary indicators, were included in the Cox regression: histology (leiomyosarcomas $v s$ other), tumour grade ( $3 v s$ other), response (complete/partial response $v s$ other), tumour location (localised vs metastatic disease) and salvage therapy with curative intention (yes $v s$ no).

\section{RESULTS}

\section{Patient characteristics}

Fifty-one patients with advanced soft-tissue sarcomas, from seven SAKK (Swiss Group for Clinical Cancer Research) centres were enrolled in the study between 10/1995 and 1/2001. As gastrointestinal stromal tumour (GIST) is now recognised as a specific entity, it was decided to exclude patients with GIST from analysis. On histopathological review, five patients were excluded from analysis because of the following characteristics: melanoma, 
Table I Patient characteristics

\begin{tabular}{|c|c|}
\hline Number of patients & 46 \\
\hline \multicolumn{2}{|l|}{ Sex } \\
\hline Male & 28 \\
\hline Female & 18 \\
\hline \multicolumn{2}{|l|}{ Performance status } \\
\hline 0 & 24 \\
\hline I & 21 \\
\hline 2 & I \\
\hline \multicolumn{2}{|l|}{ Sarcoma type } \\
\hline Leiomyosarcoma & 13 \\
\hline Malignant fibrous histiocytoma & 11 \\
\hline Angiosarcoma & 4 \\
\hline Epithelioid sarcoma & 4 \\
\hline Liposarcoma & 4 \\
\hline Neurofibrosarcoma & 4 \\
\hline Unclassified & 2 \\
\hline Alveolar rhabdomyosarcoma & I \\
\hline Synoviosarcoma & I \\
\hline Extra-skeletal osteosarcoma & । \\
\hline Malignant hemangiopericytoma & । \\
\hline \multicolumn{2}{|l|}{ Differentiation grade } \\
\hline 1 & 6 \\
\hline 2 & 14 \\
\hline 3 & 25 \\
\hline Unknown & । \\
\hline \multicolumn{2}{|l|}{ Tumour location } \\
\hline Localised & 14 \\
\hline Metastatic & 32 \\
\hline Lung & 21 \\
\hline Lymph nodes & 13 \\
\hline Liver & 6 \\
\hline Bone & 3 \\
\hline Soft tissue & 3 \\
\hline Pancreas & । \\
\hline Kidney & । \\
\hline Peritoneum & I \\
\hline
\end{tabular}

progressive disease after one cycle of the studied regimen $(n=1)$; cystosarcoma phyllodes of the breast with metastases in the lung, partial response after six cycles of treatment $(n=1)$; three GIST, progression after two chemotherapy cycles $(n=2)$ and death due to intestinal haemorrhage during the first chemotherapy cycle $(n=1)$.

Thus, a total of 46 patients (18 women and 28 men) could be evaluated. Pertinent characteristics are summarised in Table 1. The median age of these patients was $51(21-60)$ years. Except one patient had a compromised performance status WHO grade 2 , all the others had a WHO grade 0 or 1 . Leiomyosarcomas and malignant fibrohistiocytoma (MFH) were the most frequent histologies, each accounting for almost one-third of all tumour types. Tumours were grade 3 in $54 \%$ and grade 2 in $30 \%$ of patients. The six patients with grade 1 tumour $(13 \%)$ diagnosed on the biopsy of the primary had distant metastases at time of inclusion. While most patients were diagnosed with metastatic tumours, one-third presented with advanced localised disease (large peripheral primary $=5$, inoperable primary $=4$, recurrences $=5$ ).

\section{Toxicity and dose intensity}

A median of 4 (1-6) chemotherapy cycles per patient was administered, and a total of 187 cycles were analysed for toxicity. Myelosuppression was the predominant type of toxicity. Severe neutropenia WHO $\geqslant$ grade 3 was observed in $59 \%$ of cycles $(73 \%$ of patients being affected) and a febrile episode occurred in $29 \%$ (with demonstrable infection in 20\%) of cycles. One patient died of septic shock during his fourth cycle. WHO $\geqslant$ grade 3 thrombocytopenia and anaemia were observed in 39 and $27 \%$ of cycles, respectively, affecting two-third of patients.

Neurological toxicity (MD Anderson score) was observed during 11 cycles (grade 1: $n=8$; grade 3: $n=3$ ). All events could be managed by administration of methylene blue and/or discontinuation of ifosfamide. Transient elevations in creatinine levels were observed in three patients. No cases of severe renal toxicity were noted, although 17 cycles were associated with transient microscopic haematuria. Mucositis occurred in $46 \%$ of cycles but was generally moderate, reaching grade 3 or 4 in only 19 cycles (10\%). No cases of clinical heart failure were noted, although two patients had significant drops in cardiac ejection fraction from baseline. Doses were modified in $29 \%$ of cycles, invariably because of toxicity. A total of $22 \%$ chemotherapy cycles were delayed because of toxicity or upon patients' request. The dose intensity of ifosfamide could be maintained at a median of $2740 \mathrm{mg} \mathrm{m}^{-2}$ week $^{-1}$ ( $82 \%$ of the planned dose) and for doxorubicin at a median of $26 \mathrm{mg} \mathrm{m}^{-2}$ week $^{-1}$ ( $86 \%$ of the planned dose).

\section{Response and survival}

Of the 46 patients who were evaluated for response to chemotherapy, three were complete responders $(6.5 \%)$ and 19 were partial responders (41\%). The overall response rate was thus $48 \%$ (98\% CI: $33-63 \%)$. A total of 18 patients showed stable disease (39\%), and five patients showed progressive disease $(11 \%)$. The response rate was not different between localised and metastatic diseases (50 and $47 \%$ ). A partial response was observed in two among the five patients with large primaries. Broken up by histological tumour types, overall response to chemotherapy was observed in $5 / 13$ patients with leiomyosarcomas (38\%, 95\% CI: $14-68 \%)$, in $6 / 11$ patients with malignant fibrohistiocytomas (54\%, 95\% CI: $23-$ $83 \%$ ), in $4 / 4$ patients with epithelioid sarcomas, in 3/4 patients with angiosarcomas, in $1 / 4$ patients with neurofibrosarcomas and in $0 / 4$ patients with liposarcomas. Response rates were slightly higher in grade $3(14 / 25=56 \%, 95 \%$ CI: $35-76 \%)$ than in grade $1-2$ $(8 / 20=40 \%, 95 \%$ CI: $19-64 \%)$ tumours.

A total of 20 patients were treated by salvage surgery and/or radiotherapy following partial response $(n=12)$ or stable disease $(n=8)$ after chemotherapy. These salvage regimens included both surgery and radiotherapy $(n=7)$, surgery $(n=2)$ or radiotherapy $(n=1)$ in 10 patients with localised disease and surgery $(n=6)$ or radiotherapy $(n=4)$ in 10 patients with metastatic disease.

After a median follow-up of 45 months, there were 31 cases of tumour progression and 24 cases of tumour-related death. Other causes of death included coronary artery disease $(n=1)$, pulmonary embolism $(n=2)$, septic shock $(n=1)$ or remained unknown $(n=3)$. Overall, our strategy yielded a median time to progression of 16.2 months (95\% CI: $10.2-22.5$ ) and a median overall survival of 19.6 months (95\% CI: 14.2-25.5) (Figure 1). Multivariate analysis including salvage therapy, histology, grade, tumour localisation and response to chemotherapy as covariates demonstrated that salvage therapy was the most significant predictor for favourable outcomes (hazard ratio: 0.11 ; $95 \% \mathrm{CI}$ : $0.04-0.30$ ). Leiomyosarcomas were associated with significantly better outcomes than all other histological tumour types (hazard ratio: 0.27 ; $95 \%$ CI: $0.11-0.70)$. By contrast, tumour grade, localisation and tumour response to chemotherapy had any significant impact on survival (Figure 2).

\section{DISCUSSION}

In a previous phase I trial, we identified the maximum tolerated dose levels for combined administration of ifosfamide and 


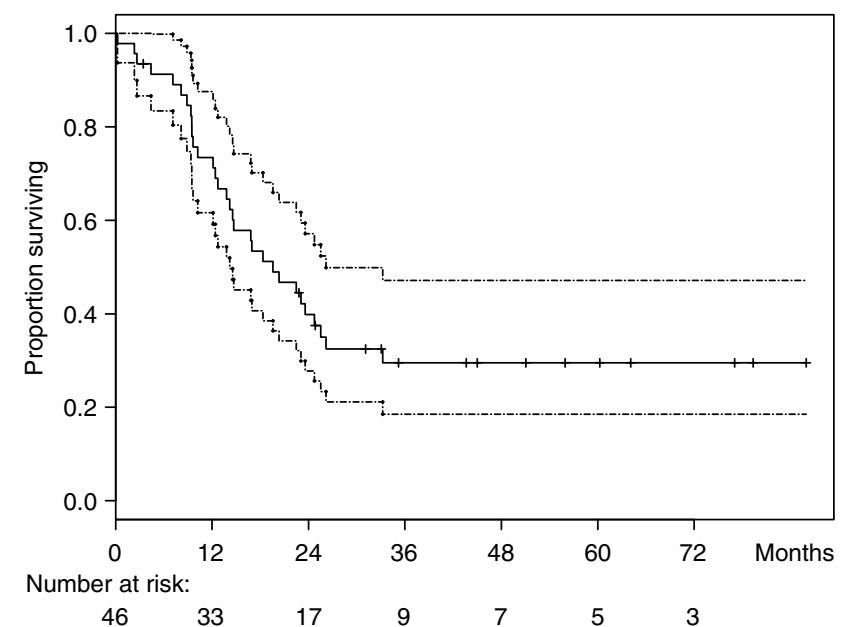

Figure I Kaplan-Meier curve for overall survival (interrupted line 95\% confidence interval).

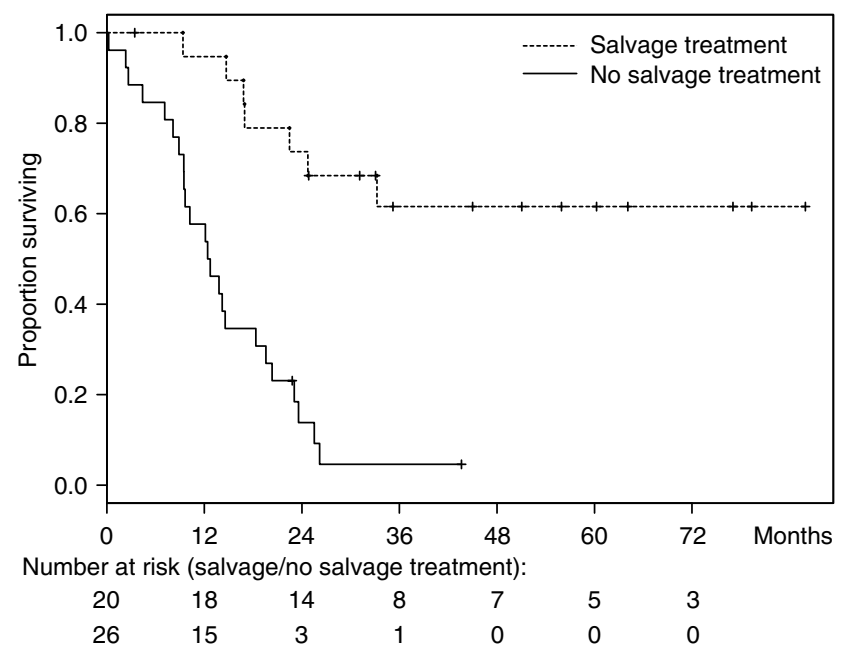

Figure 2 Overall survival of patients treated by salvage surgery and/or radiotherapy (aiming to eliminate all residual disease) in addition to chemotherapy vs patients treated by high-dose chemotherapy only.

doxorubicin (Leyvraz et al, 1998). The phase II trial herein presented was required to confirm the increased response rate suggested in that previous trial. It has successfully accomplished this purpose by demonstrating a response rate of $48 \%$ (95\% CI: $33-63 \%)$ in 46 patients with advanced soft-tissue sarcomas. Although this observed response rate did not reach the requirement being considered promising as defined by the statistical design, it is in the range of similar response rates $(40-66 \%)$ for high-dose combination of ifosfamide and doxorubicin that have been obtained in other phase-II studies (Frustaci et al, 1997; Patel et al, 1998; Reichardt et al, 1998). The most recent trials have yielded less impressive response rates $(25-23 \%)$ but were designed such that only one agent was administered at high dose levels (Le Cesne et al, 2000; Worden et al, 2005). Indeed, the efficacy of ifosfamide alone at standard dose $\left(5 \mathrm{~g} \mathrm{~m}^{-2}\right)$ was shown to be minimal $(10 \%)$ in a randomised trial (van Oosterom et al, 2002). Moreover the best schedule of ifosfamide administration is still unknown. There were suggestions that daily 2- to $4 \mathrm{~h}$-infusion might be more active than continuous infusion (Patel et al, 1997), but might be also more toxic (Antman et al, 1989).
As expected, and despite the use of haematopoietic growth factors, the combined myelotoxicity of both agents employed in our study led to severe (WHO grade 3-4) neutropenia in $59 \%$ of cycles and $73 \%$ of patients. These episodes were of short duration. Febrile neutropenia occurred in 29\% of cycles. One patient died of septic shock. Severe anaemia and thrombopenia were observed in two-thirds of patients. Based on our results, we conclude that these toxic events can be managed in a multicentre setting if adequate experience is available in the participating centres, but limited to patients aged $\leqslant 60$ years and with a performance status $<2$.

Similar toxicity profiles, with severe neutropenia in $94-100 \%$ of patients, were described in other trials (Patel et al, 1998; Reichardt et al, 1998). Lower-dose combinations led to severe neutropenia in $87-90 \%$ and severe infection in $17 \%$ of patients (Le Cesne et al, 2000; Worden et al, 2005). One of these studies involved two toxic deaths out of 40 patients, severe thrombopenia in $50-62 \%$ and severe anaemia in approximately $50 \%$ of patients (Worden et al, 2005). Even standard dose levels (ifosfamide $6 \mathrm{~g} \mathrm{~m}^{-2}$ and doxorubicin $60 \mathrm{mg} \mathrm{m}^{-2}$ and G-CSF) led to severe neutropenia in $49 \%$, anaemia in $23 \%$, and thrombopenia in $15 \%$ of patients (Worden et al, 2005). In a large-scale EORTC trial, dose levels of ifosfamide $5 \mathrm{~g} \mathrm{~m}^{-2}$ and doxorubicin $50 \mathrm{mg} \mathrm{m}^{-2}$ but without G-CSF led also to severe neutropenia in $86 \%$, and thrombopenia in $8 \%$ of patients (Le Cesne et al, 2000).

It is thus reasonable to conclude that myelosuppression should be accepted as inherent in any ifosfamide-doxorubicin combination therapy. Therefore, these regimens should only be administered in specialised centres (Benjamin, 1987). If severe toxicity is the price to be paid for improved outcomes, it might be acceptable after all.

Median overall survival in the present study was 19.6 months, with an estimated 5-year-survival rate of $30 \%$. These results are comparable with overall survival times of 18-25 months reported in other intensive-dose trials (Frustaci et al, 1997; De Pas et al, 1998; Reichardt et al, 1998). They are presumably also better than the 12 months obtained in standard-dose trials, even though the respective data may not be suitable for direct comparisons (Bramwell et al, 2003). The exploratory multivariate analysis defined that leiomyosarcoma had a better outcome compared to other histology subtypes. The prognostic value on survival of the different histologies is yet unsettled. When standard chemotherapy is used, the median overall survival was improved for liposarcoma (Van Glabbeke et al, 1999), but 5-year survivors could be found equally in all subtypes (Blay et al, 2003). If leiomyosarcomas have a very low response rate $(10 \%)$ with standard chemotherapy, in our small series, as well as in other similar ones, the response rates ranged between 30 and 75\% (Frustaci et al, 1997; Reichardt et al, 1998; Maurel et al, 2004b), potentially explaining an improved outcome.

The objection may be raised that our results were only possible because we selected patients with favourable prognostic factors and good performance status who were in a particularly good condition to tolerate such an intensive and toxic approach (Van Glabbeke et al, 1999). While this may be true, the EORTC has demonstrated (based on $4 \%$ of 1888 patients) that complete remission is not just a yardstick for chemotherapeutic success but is really the most important predictor of favourable long-term survival (Blay et al, 2003).

Trials in which high-dose ifosfamide was combined with highdose anthracylines have yielded complete remission rates of 8-20\% (Reichardt et al, 1998). In our study it was 6.5\% and might have accounted only marginally to the final results. However, a complete remission should not be solely based on chemotherapy. Salvage surgery performed after chemotherapy should also be taken into account, since patients in whom all residual disease is surgically removed will do equally well (Reichardt et al, 1998). In 117 patients that have been operated in order to render them 
without evidence of disease, a median overall survival of 19 months was obtained (Billingsley et al, 1999). In previous studies of highdose chemotherapy, salvage surgery with or without radiotherapy could be performed in $17-32 \%$ of patients and may have contributed to the improved outcomes in these series.

With these considerations in mind, high-dose chemotherapy with G-CSF support could be defined as part of a multidisciplinary strategy in the treatment of soft-tissue sarcomas, to be performed at experienced institutions only. Its goal would be to induce the most effective antitumour response available, thereby preparing the ground for salvage therapies to improve the outcome further. And future research should focus on identifying patients that might benefit form such a combined treatment approach.

\section{ACKNOWLEDGEMENTS}

This trial was partially supported by Baxter Oncology GmbH, successor in right to ASTA Medica Oncologie, Switzerland. We are indebted to Marianne Gonin for editorial assistance.

\section{REFERENCES}

Antman KH, Ryan L, Elias A, Sherman D, Grier HE (1989) Response to ifosfamide and mesna: 124 previously treated patients with metastatic or unresectable sarcoma. J Clin Oncol 7: 126-131

Benjamin RS (1987) Grade 3 nausea, vomiting, and myelosuppression or progressive, metastatic sarcoma? J Clin Oncol 5: 833-835

Billingsley KG, Lewis JJ, Leung DH, Casper ES, Woodruff JM, Brennan MF (1999) Multifactorial analysis of the survival of patients with distant metastasis arising from primary extremity sarcoma. Cancer 85: 389-395

Blay JY, van Glabbeke M, Verweij J, van Oosterom AT, Le Cesne A, Oosterhuis JW, Judson I, Nielsen OS (2003) Advanced soft-tissue sarcoma: a disease that is potentially curable for a subset of patients treated with chemotherapy. Eur J Cancer 39: 64-69

Bramwell VHC, Anderson D, Charette ML, The Sarcoma Disease Site Group (2003) Doxorubicin-based chemotherapy for the palliative treatment of adult patients with locally advanced or metastatic soft tissue sarcoma (review). The Cochrane Database Syst Rev, (3): CD003293, John Wiley and Sons, Ltd

Castellanos AM, Fields WS (1986) Grading of neurotoxicity in cancer therapy. J Clin Oncol 4: 1277-1278

Cerny T, Leyvraz S, von Briel T, Kupfer A, Schaad R, Schmitz SF, Honegger P, Sessa C, Brunner J, Boddy AV (1999) Saturable metabolism of continuous high-dose ifosfamide with mesna and GM-CSF: a pharmacokinetic study in advanced sarcoma patients. Swiss Group for Clinical Cancer Research (SAKK). Ann Oncol 10: 1087-1094

Cosetti M, Wexler LH, Calleja E, Trippett T, LaQuaglia M, Huvos AG Gerald W, Healey JH, Meyers PA, Gorlick R (2002) Irinotecan for pediatric solid tumors: the Memorial Sloan-Kettering experience. J Pediatr Hematol Oncol 24: $101-105$

De Pas T, De Braud F, Orlando L, Nole F, Munzone E, Zampino MG, Fazio N, Aapro MS, Goldhirsch A (1998) High-dose ifosfamide plus adriamycin in the treatment of adult advanced soft tissue sarcomas: is it feasible? Ann Oncol 9: 917-919

Dirix LY, Van Oosterom AT (1999) Soft tissue sarcoma in adults. Curr Opin Oncol 11: 285-295

Edmonson JH, Ryan LM, Blum RH, Brooks JS, Shiraki M, Frytak S, Parkinson DR (1993) Randomized comparison of doxorubicin alone $v s$ ifosfamide plus doxorubicin or mitomycin, doxorubicin, and cisplatin against advanced soft tissue sarcomas. J Clin Oncol 11: 1269-1275

Fata F, O'Reilly E, Ilson D, Pfister D, Leffel D, Kelsen DP, Schwartz GK, Casper ES (1999) Paclitaxel in the treatment of patients with angiosarcoma of the scalp or face. Cancer 86: 2034-2037

Fayette J, Blay JY (2005) Genetic predictors for drug resistance in soft tissue sarcoma: a review of publications in 2004. Curr Opin Oncol 17: $370-375$

Frustaci S, Buonadonna A, Galligioni E, Favaro D, De Paoli A, Lo RG, Sorio R, Tumolo S, Monfardini S (1997) Increasing 4'-epidoxorubicin and fixed ifosfamide doses plus granulocyte-macrophage colony-stimulating factor in advanced soft tissue sarcomas: a pilot study. J Clin Oncol 15: $1418-1426$

Grosso F, Demetri GD, Blay JY, Judson I, Le Cesne A, Spreafico C, Jimeno J, Pilotti S, D'Incalci M, Casali PG (2006) Patterns of tumor response to trabectedin (ET743) in myxoid liposarcomas. J Clin Oncol, ASCO Annual Meeting Proceedings, 9511

Guillou L, Coindre JM, Bonichon F, Nguyen BB, Terrier P, Collin F, Vilain MO, Mandard AM, Le Doussal V, Leroux A, Jacquemier J, Duplay H, Sastre-Garau X, Costa J (1997) Comparative study of the National Cancer Institute and French Federation of Cancer Centers Sarcoma Group grading systems in a population of 410 adult patients with soft tissue sarcoma. J Clin Oncol 15: 350-362
Hensley ML, Maki R, Venkatraman E, Geller G, Lovegren M, Aghajanian C, Sabbatini P, Tong W, Barakat R, Spriggs DR (2002) Gemcitabine and docetaxel in patients with unresectable leiomyosarcoma: results of a phase II trial. J Clin Oncol 20: 2824-2831

Hryniuk W, Goodyear M (1990) The calculation of received dose intensity. J Clin Oncol 8: 1935-1937

Judson I (2004) Systemic therapy of soft tissue sarcoma: an improvement in outcome. Ann Oncol 15(Suppl 4): iv193-iv196

Küpfer A, Aeschlimann C, Wermuth B, Cerny T (1994) Prophylaxis and reversal of ifosfamide encephalopathy with methylene-blue. Lancet 343: $763-764$

Le Cesne A, Antoine E, Spielmann M, Le Chevalier T, Brain E, Toussaint C, Janin N, Kayitalire L, Fontaine F, Genin J, Vanel D, Contesso G, Tursz T (1995) High-dose ifosfamide: circumvention of resistance to standard-dose ifosfamide in advanced soft tissue sarcomas. J Clin Oncol 13: $1600-1608$

Le Cesne A, Judson I, Crowther D, Rodenhuis S, Keizer HJ, Van Hoesel Q, Blay JY, Frisch J, Van Glabbeke M, Hermans C, Van Oosterom A, Tursz T, Verweij J (2000) Randomized phase III study comparing conventional-dose doxorubicin plus ifosfamide $v s$ highdose doxorubicin plus ifosfamide plus recombinant human granulocytemacrophage colony-stimulating factor in advanced soft tissue sarcomas: A trial of the European Organization for Research and Treatment of Cancer/Soft Tissue and Bone Sarcoma Group. J Clin Oncol 18: $2676-2684$

Leyvraz S, Bacchi M, Cerny T, Lissoni A, Sessa C, Bressoud A, Hermann R (1998) Phase I multicenter study of combined highdose ifosfamide and doxorubicin in the treatment of advanced sarcomas. Swiss Group for Clinical Research (SAKK). Ann Oncol 9: $877-884$

Maurel J, Buesa J, Lopez-Pousa A, del Muro XG, Quintana MJ, Martin J, Casado A, Martinez-Trufero J, de Las PR, Balana C (2004a) Salvage surgical resection after high-dose ifosfamide (HDIF) based regimens in advanced soft tissue sarcoma (ASTS): a potential positive selection bias a study of the Spanish group for research on sarcomas (GEIS). J Surg Oncol 88: $44-49$

Maurel J, Fra J, Lopez-Pousa A, Garcia del Muro X, Balana C, Casado A, Martin J, Martinez-Trufero J, de las Penas R, Buesa JM (2004b) Sequential dose-dense doxorubicin and ifosfamide for advanced soft tissue sarcomas: a Phase II trial by the Spanish Group for Research on Sarcomas (GEIS). Cancer 100: $1498-1506$

O'Bryan RM, Luce JK, Talley RW, Gottlieb JA, Baker LH, Bonadonna G (1973) Phase II evaluation of adriamycin in human neoplasia. Cancer 32: $1-8$

Oken MM, Creech RH, Tormey DC, Horton J, Davis TE, McFadden ET, Carbone PP (1982) Toxicity and response criteria of the Eastern Cooperative Oncology Group. Am J Clin Oncol 5: 649-655

Patel SR, Vadhan-Raj S, Burgess MA, Plager C, Papadopolous N, Jenkins J, Benjamin RS (1998) Results of two consecutive trials of dose-intensive chemotherapy with doxorubicin and ifosfamide in patients with sarcomas. Am J Clin Oncol 21: 317-321

Patel SR, Vadhan-Raj S, Papadopolous N, Plager C, Burgess MA, Hays C, Benjamin RS (1997) High-dose ifosfamide in bone and soft tissue sarcomas: results of phase II and pilot studies - dose-response and schedule dependence. J Clin Oncol 15: 2378-2384

Reichardt P, Tilgner J, Hohenberger P, Dorken B (1998) Dose-intensive chemotherapy with ifosfamide, epirubicin, and filgrastim for adult patients with metastatic or locally advanced soft tissue sarcoma: a phase II study. J Clin Oncol 16: $1438-1443$ 
Santoro A, Tursz T, Mouridsen H, Verweij J, Steward W, Somers R, Buesa J, Casali P, Spooner D, Rankin E, Kirkpatrick A, van Glabbeke M, van Oosterom A (1995) Doxorubicin vs CYVADIC vs doxorubicin plus ifosfamide in first-line treatment of advanced soft tissue sarcomas: a randomized study of the European Organization for Research and Treatment of Cancer Soft Tissue and Bone Sarcoma Group. J Clin Oncol 13: $1537-1545$

Van Glabbeke M, van Oosterom AT, Oosterhuis JW, Mouridsen H, Crowther D, Somers R, Verweij J, Santoro A, Buesa J, Tursz T (1999) Prognostic factors for the outcome of chemotherapy in advanced soft tissue sarcoma: an analysis of 2185 patients treated with anthracyclinecontaining first-line regimens - a European Organization for Research and Treatment of Cancer Soft Tissue and Bone Sarcoma Group Study. J Clin Oncol 17: $150-157$

van Oosterom AT, Mouridsen HT, Nielsen OS, Dombernowsky P, Krzemieniecki K, Judson I, Svancarova L, Spooner D, Hermans C, Van
Glabbeke M, Verweij J (2002) Results of randomised studies of the EORTC Soft Tissue and Bone Sarcoma Group (STBSG) with two different ifosfamide regimens in first- and second-line chemotherapy in advanced soft tissue sarcoma patients. Eur J Cancer 38: 2397-2406

Worden FP, Taylor JM, Biermann JS, Sondak VK, Leu KM, Chugh R, McGinn CJ, Zalupski MM, Baker LH (2005) Randomized phase II evaluation of $6 \mathrm{~g} \mathrm{~m}^{-2}$ of ifosfamide plus doxorubicin and granulocyte colony-stimulating factor (G-CSF) compared with $12 \mathrm{~g} \mathrm{~m}^{-2}$ of ifosfamide plus doxorubicin and G-CSF in the treatment of poor-prognosis soft tissue sarcoma. J Clin Oncol 23: 105-112

World Health Organization (1979) Handbook for Reporting results for Cancer Treatment, 48, WHO offset publication No 48 (ed). WHO: Geneva

Yovine A, Riofrio M, Blay JY, Brain E, Alexandre J, Kahatt C, Taamma A, Jimeno J, Martin C, Salhi Y, Cvitkovic E, Misset JL (2004) Phase II study of ecteinascidin-743 in advanced pretreated soft tissue sarcoma patients. J Clin Oncol 22: 890-899 